\title{
Reportar condicionais: uma questão de ponto de vista
}

\author{
Reporting conditionals: a matter of viewpoint
}

\author{
Lílian Ferrari \\ Universidade Federal do Rio de Janeiro
}

\begin{abstract}
This paper focuses on embedded conditional constructions in Brazilian Portuguese. Based on mental space theory, the analysis shows that the traditionally accepted notion of coherent epistemic stance has to be reviewed in order to account for embedded conditionals which occur in indirect reported speech. Since non-coherent epistemic stance may also occur, it is argued that the cognitive notion of Viewpoint can provide a general explanation for the occurrence of both coherent and non-coherent embedded conditionals.
\end{abstract}

\section{Keywords}

Conditionals; Epistemic stance; Embedding; Viewpoint.

\section{Resumo}

Este trabalho enfoca construções condicionais encaixadas no discurso reportado, com o objetivo de investigar as relações entre estrutura sintática e informações semântico-pragmáticas associadas a essas construções. A investigação de condicionais atestadas em textos escritos demonstra que a visão tradicionalmente aceita de uniformidade de postura epistêmica em condicionais preditivas (FILLMORE, 1990; DANCYGIER; SWEETSER, 2005) deve ser reavaliada, tendo em vista que casos de não-uniformidade também são observados nesses contextos. Argumenta-se que o primitivo discursivo de Ponto de Vista, em seus desdobramentos na configuração de espaços mentais, 
permite uma explicação unificada para as diferentes combinações modo-temporais que as condicionais encaixadas em Espaços de Fala podem apresentar (CUTRER, 1994; FAUCONNIER, 1997).

\section{Palavras-chave}

Condicionais; Postura epistêmica; Encaixe; Ponto de vista. 


\section{Introdução}

idéia de que construções gramaticais são pareamentos de forma e
significado caracteriza um dos principais programas de pesquisa da
lingüística contemporânea (FILLMORE; KAY; O'CONNOR, 1988; GOLDBERG,1995, 2006; LANGACKER, 1987, 1991; TOMASELLO, 2005). Estendendo a noção de signo lingüístico para o âmbito da gramática, essa abordagem pretende resgatar a importância do caráter simbólico da linguagem, contrapondose à visão gerativa tradicional que prioriza o estabelecimento de regras algorítmicas capazes de especificar as estruturas sintáticas de uma língua (CHOMSKY, 1968, 1980). Ainda com relação ao paradigma saussureano, pode-se dizer que a gramática de construções retoma o conceito de arbitrariedade relativa do signo, ao postular que a gramática constitui uma rede de construções relacionadas entre si e motivadas por laços de herança de natureza semântico-pragmática.

O presente trabalho enfoca construções condicionais preditivas encaixadas no discurso reportado, com o objetivo de rediscutir a noção de uniformidade de postura epistêmica, tradicionalmente aceita na literatura referente a condicionais (FILLMORE, 1990; DANCYGIER, 1998; DANCYGIER; SWEETSER, 2005). Com base em exemplos atestados em corpus eletrônico, a análise demonstra que a exigência de uniformidade, refletida em sequiências compatíveis de tempos verbais, não é uma restrição sintática inerente às construções condicionais, mas decorre de fatores discursivo-pragmáticos que podem ser tratados adequadamente com base nas ferramentas teóricas oferecidas pela teoria dos espaços mentais.

Partindo-se de estudos anteriores (CUTRER, 1994; FAUCONNIER, 1997), que apontam a existência de diferentes possibilidades de alocação do ponto de vista (PV) no momento do encaixe de construções argumentais simples em Espaços de Fala (diretamente na Base; no Espaço de Fala via Base; ou diretamente no Espaço de Fala), argumenta-se que, no encaixe de construções condicionais, a escolha com relação ao estabelecimento de ponto de vista exibe graus adicionais de complexidade: a) o PV pode recair sobre a Base, de onde 
são introduzidos os espaços condicionais $\mathrm{P}$ e Q; b) o $\mathrm{PV}$ pode recair sobre o Espaço de Fala, a partir do qual são criados os espaços $\mathrm{P}$ e Q; c) o PV pode recair sobre a Base para a criação do espaço $P$ e deslocar-se para o Espaço de Fala para a criação do espaço Q. Nos dois primeiros casos, fixa-se um único ponto de vista e a postura epistêmica (neutra ou distanciada) será uniforme; já em "c", verifica-se duplicidade de ponto de vista e não-uniformidade de postura epistêmica, que muda de neutra para distanciada.

O trabalho está organizado da seguinte forma: na seção 2, são delineados os principais pressupostos teóricos que embasam o tratamento cognitivista das construções condicionais; a seção 3, resumem-se achados referentes à correlação entre discurso reportado e estratégias de estabelecimento de ponto de vista, especificando-se, na seção 3.1, as estratégias de encaixe de construções condicionais no discurso reportado; as seções 4 e 5 analisam ocorrências reais de condicionais encaixadas no discurso reportado em textos escritos, enfocando casos de uniformidade de postura epistêmica e associandose casos de não-uniformidade a estratégias de deslocamento de ponto de vista.Por fim, discutem-se casos de condicionais encaixadas em espaços epistêmicos, com o objetivo de demonstrar que as estratégias de estabelecimento de ponto de vista são menos flexíveis nesses contextos.

\section{Espaços mentais e condicionais}

A teoria dos espaços mentais prevê que a compreensão e a produção da linguagem envolvem a construção de domínios cognitivos organizados e interconectados, que são independentes da linguagem, mas dos quais a linguagem depende para a interpretação do significado. As expressões lingüísticas são concebidas como manifestações superficiais dessas construções subjacentes, altamente abstratas; as sentenças fornecem instruções parciais e subespecificadas para: a construção de domínios; a subdivisão e o fracionamento da informação em diferentes domínios; a estruturação dos elementos e relações dentro de cada domínio; e a construção de conexões entre elementos em domínios diferentes e conexões entre esses mesmos domínios (FAUCONNIER 1994, 1997; FAUCONNIER; SWEETSER, 1996, FAUCONNIER; TURNER, 2002).

A interpretação do discurso resulta da construção de uma configuração de espaços hierarquicamente relacionados e interconectados. À medida que 
cada sentença é produzida, a configuração de espaços é dinamicamente atualizada, baseada em pistas lexicais e gramaticais fornecidas pela sentença.

Os espaços são pragmaticamente elaborados pelo conhecimento subjacente formatado em Frames, que se desdobram em Enquadres Lexicais (recortes no interior de uma determinada cena, sob a perspectiva das escolhas lexicais) e Modelos Cognitivos Idealizados (MCIs) (FILLMORE, 1982; LAKOFF, 1987). Além disso, são também elaborados por processos de inferenciação e raciocínio.

À medida que o discurso se desenvolve, novos espaços são criados em função de pistas fornecidas por "construtores de espaços" (space-builders), por marcadores gramaticais tais como tempo e modo, ou por informação pragmática. Os construtores de espaços apresentam-se de formas variadas: sintagmas preposicionais, conectivos, cláusulas que exigem complementos, entre outros.

No caso das condicionais, verifica-se a criação de uma configuração de espaços que serve como moldura informacional com potencial dedutivo. A prótase da condicional possibilita a introdução de um espaço mental $\mathrm{P}$, que funciona como um operador sobre o discurso subseqüente, e abre um domínio discursivo por enquadramento específico. Sweetser (1990) assinala que em condicionais do tipo “Se P, (então) Q", o evento P é uma condição suficiente (e, em alguns casos, necessária) para a ocorrência do evento Q. ${ }^{1}$ Visto que as noções de necessidade e suficiência se relacionam semanticamente à noção de causalidade, pode-se concluir que as construções condicionais são projeções hipotéticas de manifestações causais diretas.

Tais projeções, segundo a autora, podem atuar em três domínios distintos: de conteúdo, epistêmico e pragmático. Nas condicionais de conteúdo, a realização do evento ou estado de coisas descrito na prótase é uma condição para a realização do evento ou estado de coisas descrito na apódose. Essa condição pode ser conceptualizada de modo neutro (Se o Fluminense ganhar, jogará a Libertadores) ou de modo distanciado (Se o Fluminense ganhasse, jogaria a Libertadores). No domínio epistêmico, as condicionais expressam a idéia de que o conhecimento do evento ou estado de coisas expresso na prótase seria uma condição suficiente para o estabelecimento da conclusão expressa na apódose (Se o Fluminense jogou o Mundial, é porque ganhou a Libertadores). As condicionais pragmáticas, por sua vez, expressam a realização de um ato de fala representado na apódose, com base no estado de coisas descrito na prótase ( $\mathrm{Se}$ precisar de ajuda, meu nome é Cris). 


\subsection{Postura epistêmica e primitivos discursivos}

Considerando as condicionais de conteúdo, Fillmore (1990) propôs a noção de postura epistêmica, que indica a suposição do falante sobre a realidade descrita em P. $^{2}$ Segundo o autor, a relação epistêmica que o falante estabelece com o mundo representado na condicional poderá ser de dois tipos: o falante o concebe como distinto do mundo real (postura epistêmica contrafactual), ou exime-se de indicar o status do mundo alternativo representado na condicional (postura epistêmica neutra). Os exemplos abaixo ilustram essas possibilidades, respectivamente: ${ }^{3}$

(1) Se o Fluminense ganhasse a Copa do Brasil, jogaria a Libertadores.

(2) (Eu não sei, mas) se o Fluminense ganhar a Copa do Brasil, jogará a Libertadores.

Em estudos recentes em Lingüística Cognitiva, as construções condicionais têm merecido análises baseadas em configurações de espaços mentais, que incluem normalmente três primitivos discursivos: Base, Ponto de Vista e Foco. Esses primitivos podem ser assim definidos (DINSMORE, 1991; CUTRER, 1994; FAUCONNIER, 1997):

Base - funciona como âncora da configuração; em geral, é o espaço que serve de ponto de partida para o discurso, e ao qual se pode sempre retornar.

Ponto de Vista - é o espaço a partir do qual outros espaços são criados ou acessados.

Foco - é o espaço ao qual se adiciona conteúdo.

Retomemos os exemplos (1) e (2), representando-os diagramaticamente:

(1) Se o Fluminense ganhasse a Copa do Brasil, jogaria a Libertadores. 


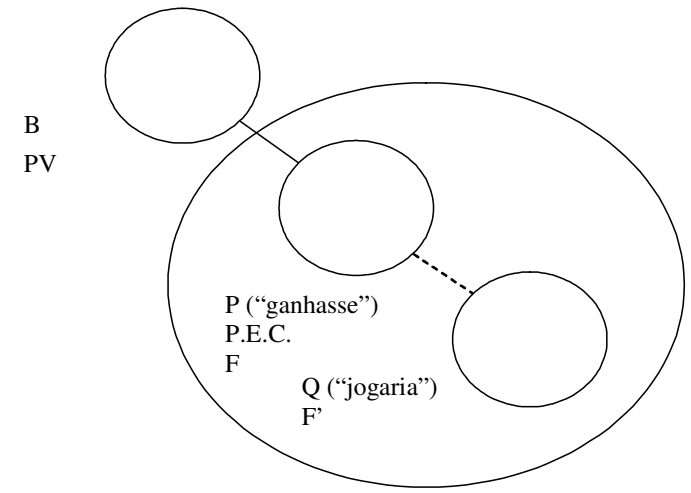

Diagrama 1 - Configuração referente ao exemplo (1)

$\mathrm{B}=$ base; $\mathrm{PV}=$ ponto de vista; $\mathrm{P}=$ prótase; $\mathrm{Q}=$ apódose;

$\mathrm{PEC}=$ postura epistêmica contrafactual; $\mathrm{F}=$ foco; $\quad \mathrm{F}^{\prime}=$ foco'

O diagrama acima evidencia o fato de que, tomando-se a Base como PV, o Espaço Pé construído a partir de uma postura epistêmica contrafactual. Além disso, é o espaço ao qual inicialmente se adiciona estrutura (Foco), podendo ser co-temporal ou futuro em relação à Base. $\mathrm{O}$ Espaço Q é então construído no interior do domínio condicional, mantendo-se o PV na Base, e adicionando-se nova estrutura a esse espaço (Foco').

(2) Se o Fluminense ganhar a Copa do Brasil, jogará a Libertadores.

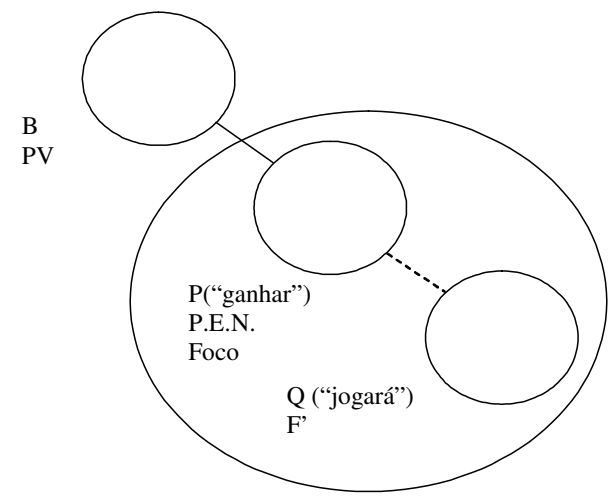

Diagrama 2 - Configuração do exemplo (2)

$\mathrm{B}=$ base; $\mathrm{PV}=$ ponto de vista; $\mathrm{P}=$ prótase; $\mathrm{Q}=$ apódose; $\mathrm{PEN}=$ postura epistêmica neutra; $F=$ foco; $\quad F^{\prime}=$ foco' 
O diagrama 2 assemelha-se ao anterior em termos de construção dos Espaços Pe Q e de alocação de PV e Foco. A diferença entre os dois diagramas reside no fato de que, no Diagrama 2, o Espaço P é construído a partir de uma postura epistêmica neutra.

\section{Discurso Reportado e Ponto de Vista}

Em se tratando do discurso reportado, Cutrer (1994) demonstrou que percursos temporais específicos são criados na configuração de espaços mentais. Segundo a autora, os verbos dicendi estabelecem espaços que fracionam o conteúdo do que é dito, dentro dos seguintes moldes:

a . o Ponto de Vista é preenchido pelo falante ou pelo experienciador do evento de fala reportado;

b. oEspaço de Fala e todos os espaços subordinados ao Espaço de Fala constituem um Domínio de Fala, de modo que configurações contendo um Domínio de Fala têm dois Pontos de Vista inerentes, um da Base e outro do Espaço de Fala.

c. Os espaços do Domínio de Fala têm status de FATO ou PREDIÇÃO em relação ao Espaço de Fala.

d. Espaços do Domínio de Fala podem ser acessados através dos seguintes percursos temporais: diretamente do Espaço de Fala, diretamente da Base, da Base passando pelo Espaço de Fala.

Com relação aos tipos de acessos descritos acima, destaquemos os seguintes exemplos, adaptados de Fauconnier (1997, p. 89-92):

I - Acesso ao Domínio de Fala diretamente do Espaço de Fala:

(3) João anunciará à meia-noite que queimou os documentos duas horas antes.

Em (3), o evento de fala (anúncio de João) é posterior à Base, tendo o status de predição; portanto, é codificado pelo futuro do indicativo (anunciará). Com relação ao evento reportado (queima dos documentos), o Espaço de Fala passa a ser o PV, como evidencia o uso do pretérito perfeito (queimou). Esse percurso temporal pode ser assim representado: 
(Ia) Base

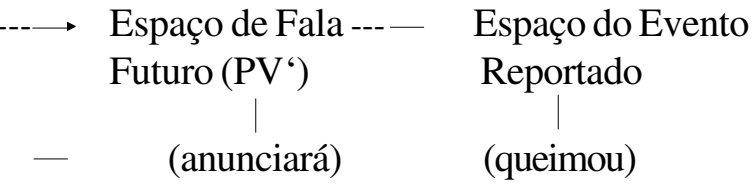

II - Acesso ao Domínio de Fala diretamente da Base:

(4) João anunciou no início da semana que ele queimará os documentos amanhã.

Em (4), o evento de fala (anúncio de João) é anterior à Base, tendo o status de fato. Com relação ao evento reportado (queima dos documentos), a Base continua sendo o PV, como evidencia a escolha do futuro do indicativo (queimará). ${ }^{4}$ Nesse caso, o percurso temporal é o seguinte:

(IIa) Base (PV)
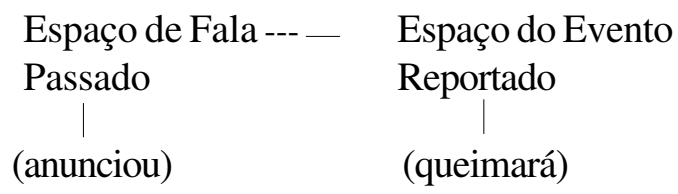

III - Acesso ao Domínio de Fala do Espaço de Fala (via Base):

(5) Tom anunciou ontem que ele queimaria os documentos dois dias depois.

Em (5), o evento de fala (anúncio de João) é anterior à Base, tendo o status de fato; é, portanto, codificado pelo pretérito perfeito (anunciou). Com relação ao evento reportado (queima dos documentos), o PV desloca-se da Base para o Espaço de Fala, como evidencia o uso do futuro do pretérito (queimaria). Esse percurso temporal pode ser assim representado:

$\begin{array}{lll}\text { (IIIa) Base (PV) --- - } & \text { Espaço de Fala --- }- & \text { Espaço do Evento } \\ & \text { Passado (PV`) } & \text { Reportado } \\ \mid & \text { (anunciou) } & \text { (queimaria) }\end{array}$

Como os esquemas (I) a (III) indicam, o trabalho de Cutrer (1994) abriu caminho para a compreensão das relações entre escolhas modo-temporais e ponto de vista em construções de estrutura argumental simples encaixadas em Espaços de Fala. Nas seções a seguir, analisar-se-á fenômeno semelhante em um novo contexto sintático: o das construções condicionais encaixadas nesses espaços. 


\subsection{O encaixe de condicionais}

Como vimos, o reconhecimento de que a postura epistêmica do falante determina escolhas modo-temporais constitui uma das importantes contribuições da investigação sobre as construções condicionais. Sendo a postura epistêmica definida como a associação ou dissociação mental do falante com o mundo descrito na prótase, as condicionais caracterizam-se por exibirem postura hipotética ou contrafactual (FILLMORE, 1990). ${ }^{5}$

Quando o falante mantém uma postura epistêmica hipotética, a condicional sinaliza neutralidade (não há associação nem dissociação mental com o evento ou estado de coisas expresso em P). É o que ocorre em construções como $S e$ chover, o jogo será cancelado. Já nos casos que evidenciam postura epistêmica contrafactual, a condicional sinaliza distanciamento (o falante assume que há divergência entre o estado de coisas descrito em $\mathrm{P}$ e o mundo real). Por exemplo, Se chovesse, o jogo seria cancelado refere-se a uma situação presente ou futura, em que o falante considera improvável que chova.

Como ilustram os exemplos acima, a postura epistêmica é tradicionalmente tratada como um fenômeno unificado e coerente: uma vez que se estabelece uma postura hipotética ou contrafactual para a prótase $\mathrm{P}$, a mesma postura é consequientemente herdada pela apódose Q. Nas condicionais hipotéticas do Português, a escolha do futuro do subjuntivo em $\mathrm{P}$ (por exemplo, Se chover) costuma requerer a escolha de tempos do futuro em Q (o jogo será canceladol o jogo vai ser cancelado). ${ }^{6}$ Sendo assim, construções como Se chover, o jogo seria cancelado não são normalmente atestadas. Por outro lado, em condicionais contrafactuais, o uso do pretérito imperfeito do subjuntivo (Se chovesse ) não indica passado cronológico, mas distância epistêmica. Coerentemente, a apódose preserva a postura epistêmica de distanciamento através do uso do futuro do pretérito (o jogo seria cancelado). Mais uma vez, em função da pressão por coerência, sentenças como Se chovesse, o jogo será cancelado também não costumam ser atestadas em textos falados ou escritos.

Observa-se, entretanto, que embora a uniformidade de postura epistêmica pareça ser a situação não-marcada, é possível relativizar essa generalização nos casos em que a construção condicional ocorre no discurso reportado. Assim, quando existe um Espaço de Fala no qual a condicional se encaixa, parece haver graus adicionais de liberdade. Em casos como Ele disse que se $P, Q$, verificase uma dupla possibilidade de encaixe, que tanto pode ser marcado através da 
conformidade dos verbos do espaço condicional à estrutura do espaço passado (Ele disse que se chovesse, o jogo seria cancelado), quanto através da nãoassimilação da estrutura temporal do espaço passado pela condicional encaixada (Ele disse que, se chover, o jogo será cancelado). Além disso, há ainda a possibilidade de flexibilização do referido encaixe, de modo que a prótase não assimile a estrutura temporal de passado, enquanto que a apódose demonstre conformidade a essa mesma estrutura (Ele disse que, se chover, o jogo seria cancelado).

No caso de construções complexas como as condicionais, o que se verifica é que a assimilação ou não da estrutura temporal do Espaço de Fala pela construção condicional encaixada decorre de diferentes possibilidades de estabelecimento do Ponto de Vista (PV). Com base nessa observação, a análise do fenômeno nas seções subsequientes será organizada em torno dos seguintes argumentos principais:

a. o PV pode ser mantido na Base, de onde são criados os espaços P e Q (ex.: Ela disse que, se chover, o jogo será cancelado).

b. o PV transfere-se para o Espaço de Fala Passado, via Base, de onde são criados os espaços P e Q ( ex.: Ela disse que, se chovesse, o jogo seria cancelado).

c. o Espaço P é criado tomando-se a Base como PV, enquanto o espaço Q, parte da Base, mas adota o Espaço de Fala Passado como PV (ex.: Ela disse que, se chover, o jogo seria cancelado)

Nos casos "a" e "b" acima (em que a estrutura temporal da condicional é assimilada pela estrutura temporal de passado do Espaço de Fala ou em que a estrutura temporal da condicional não sofre assimilação, mas mantém-se vinculada ao espaço Base, respectivamente), verifica-se a manutenção do ponto de vista em um único espaço e a decorrente uniformidade de postura epistêmica. Entretanto, no caso “c", verifica-se flexibilização do ponto de vista, que se desloca da Base para o Espaço de Fala Passado, acarretando uma estrutura epistêmica não-uniforme.

Essas possibilidades serão detalhadas nas seções subseqüentes, com base em exemplos coletados em sites de busca na internet (google) e em corpus eletrônico, que disponibiliza dados do português brasileiro escrito (http://corpusdoportugues.org). 


\section{Condicionais reportadas e uniformidade de postura epistêmica}

Com relação a sentenças que apresentam estrutura argumental simples, como "Ana viajará às duas", o que se verifica é que tais sentenças podem ser posteriormente reportadas mantendo-se o Ponto de Vista na Base ou deslocandoo, via Base, para o Espaço de Fala Passado ( "Ela disse que Ana viajará às duas" ou "Ela disse que Ana viajaria às duas"). No primeiro caso, a escolha da forma "viajará"indica que o PV mantém-se na Base. No segundo caso, o deslocamento do PV da Base para o Espaço de Fala Passado exigiu que o verbo "viajar" adotasse a marcação temporal de futuro do pretérito ("viajaria"). ${ }^{7}$

No caso das condicionais encaixadas, a situação torna-se um pouco mais complexa, já que há dois espaços (Pe Q) subordinados ao Espaço de Fala. A situação não-marcada é que os espaços $\mathrm{Pe} Q \mathrm{Q}$ sejam tratados de forma uniforme (criados a partir do mesmo PV). Como no caso de encaixe de sentenças com estrutura argumental simples, os novos espaços podem ser criados a partir do Espaço Base ou do Espaço Passado, via Base. Se o PV é mantido na Base, a estrutura temporal da condicional permanece inalterada em relação à sua estrutura original, como ilustra o exemplo a seguir:

(6) O ministro não quis adiantar o seu voto, mas disse que se não houver quorum na sessão extraordinária (oito ministros presentes), ele decidirá "ad referendum”. (Jornal Agência do Estado, Santa Catarina, 1996/1997)

O exemplo acima mescla elementos de discurso indireto e direto. Com relação à estrutura dêitica, verifica-se que a condicional reportada é alterada com relação ao pronome "ele" e ao sufixo verbal de $3^{\text {a }}$ pessoa do plural (decidiráa ), já que a fala original não poderia ter utilizado esses elementos (provavelmente, $o$ que foi dito foi algo como "Se não houver quórum..., eu decidirei..."). Entretanto, com relação à estrutura temporal, como ocorreria em caso de discurso direto, a fala reportada mantém os tempos verbais da fala original (futuro do subjuntivo/ futuro do presente).

No exemplo (6), portanto, a condicional encaixada exibe postura epistêmica neutra e uniforme, uma vez que o PV mantém-se na Base, conforme o Diagrama 3 a seguir: 


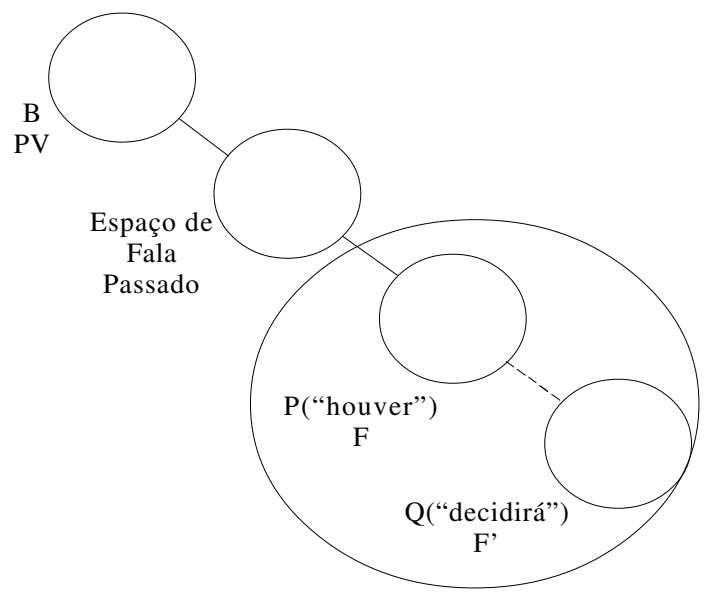

Diagrama 3 - Configuração referente ao exemplo 6 (O ministro disse que se não houver quórum na sessão extraordinária..., ele decidirá "ad referendum").

Outra possibilidade de manutenção de ponto de vista é a assimilação completa da estrutura temporal da condicional pelo Espaço Passado. Há casos em que o PV tem que ser mantido no passado porque o evento descrito não tem mais validade no presente. O exemplo a seguir ilustra esse fenômeno:

(7) "Saí da Globo porque queria mudar para Nova York, mas meu ex-marido foi ao Boni (José Bonifácio de Oliveira Sobrinho, vice-presidente da emissora ) e disse que se a Globo me contratasse aqui ele sairia da emissora", conta. (O Estado de São Paulo, 1997)

Em relação ao exemplo acima, o contexto indica que a reconstituição adequada da condicional originalmente pronunciada seria algo como "Se a Globo a contratar, sairei da emissora". A estrutura neutra "Se P (futuro do subjuntivo), Q (futuro do indicativo)" funcionou como ponto de partida para a implementação de uma camada de passado no momento do encaixe, gerando a estrutura "Se $\mathrm{P}$ (pretérito imperfeito do subjuntivo), Q (futuro do pretérito"). O Diagrama 4 representa o encaixe: 


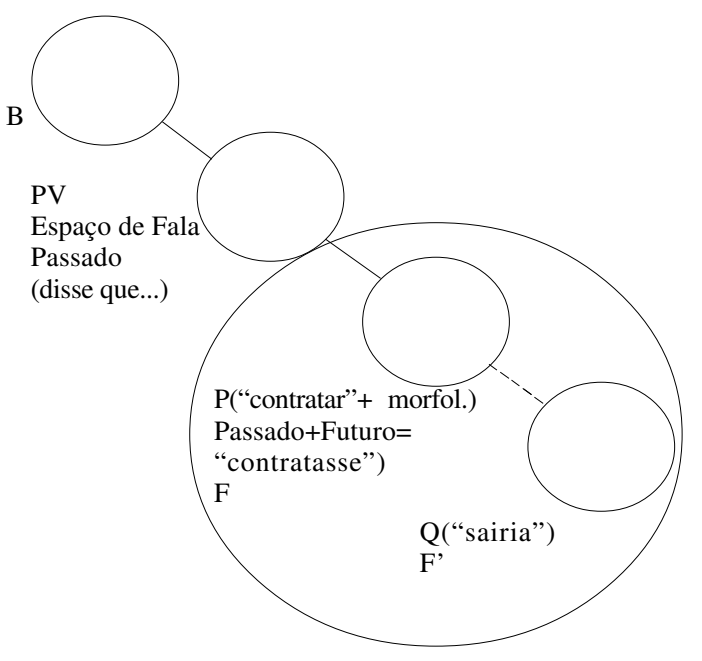

Diagrama 4 - Configuração referente a o exemplo 7 ( “...disse que se a Globo me contratasse aqui ele sairia da emissora”).

Diferentemente do que ocorreu no exemplo (7), o evento descrito na condicional poderia ser futuro não só em relação ao Espaço de Fala, mas também em relação ao Espaço Base ("hoje"). Nesse caso, haveria a opção entre manter o PV na Base ou deslocá-lo para o Espaço de Fala. No exemplo (8), em que o evento descrito na condicional é também futuro em relação à Base, escolheuse o deslocamento do ponto de vista para o passado:

(8) Após a decisão, o ministro relator Ilmar Galvão disse que se recebesse o processo..., na segunda-feira assinaria o despacho fixando prazos para as diligências e indicando os novos peritos. (Folha de São Paulo, 1994)

No exemplo acima, seria perfeitamente aceitável um encaixe do tipo Ilmar Galvão disse que se receber o processo, na segunda-feira assinará o despacho... É possível que a opção de deslocar o PV para o Espaço de Fala Passado esteja relacionada a fatores pragmáticos, por exemplo, a sinalização da perspectiva do falante reportado, sem que seja necessário o comprometimento do jornalista com essa perspectiva. Em termos de configuração de espaços mentais, o exemplo (8) comporta-se de forma semelhante ao exemplo (7) e sua representação diagramática. 
Por fim, é possível que o uso do pretérito imperfeito do subjuntivo na prótase reflita também a não-assimilação da estrutura temporal do Espaço de Fala Passado pela condicional. Isso pode ocorrer quando a condicional originalmente pronunciada já apresentava estrutura distanciada, como é o caso do exemplo a seguir: ${ }^{8}$

(9) Cristina ficou furiosa e disse que se naquela companhia houvesse alguma justiça, a vedete seria mesmo ela, já estava cheia desses papelórios de mocinha, pra lá de enjoativos, sabia cantar e dançar e tinha boas pernas, aliás cantava e dançava e não recebia (Queiroz, Dinah Silveira de, 1954, AMuralha)

Em (9), o contexto discursivo demonstra que a condicional reportada já era originalmente distanciada (se houvesse alguma justiça, ...). Nesse caso, o PV continua na Base; a diferença com relação aos exemplos anteriores é que a condicional encaixada já exibia tempo verbal no pretérito em função da sinalização de postura epistêmica negativa.

\section{Condicionais reportadas e flexibilidade de ponto de vista}

$\mathrm{Na}$ seção anterior, analisamos as relações entre localização do PV e escolhas modo-temporais nos casos em que se mantém a uniformidade de postura epistêmica. A presente seção abordará uma outra possibilidade: a de que a mudança de PV da Base para o Espaço de Fala Passado acarrete nãouniformidade de postura epistêmica. Observemos os seguintes exemplos, retirados de atas de reuniões de trabalho:

(10) (Sylvio Petrus) Disse que se for perguntado se concorda ou não com uma carreira única para os docentes, a resposta seria a de que não tem posição. (www.andes.org.br/cn_carreira/Relat\%F3rio\%201GT\%20 MEC_ANDES_13\%20mar\%202006.pdf)

(11) Hans comentou que se Santa Maria assumir toda a manutenção, a equipe atual poderia ser alocada a outros projetos, provavelmente em outras Unidades. (www.cgi.unicamp.br/zope/database/pdf/atas/ reuniao_02-10-2002.pdf)

Nos exemplos (10) e (11), o que se verifica é uma duplicidade de ponto de vista. Na introdução da prótase, o PV é mantido na Base; para a apódose, 
entretanto, o redator, partindo da Base, desloca o PV para o Espaço de Fala Passado. A flexibilidade de postura epistêmica decorre, portanto, dessa duplicidade.

Em textos literários, a flexibilidade de postura epistêmica pode servir como recurso de aproximação com a oralidade, como ilustra o exemplo a seguir:

(12) Mas quando eu falei de aumentar o preço, vixe! Os home viraro bicho. Um deles teve lá em casa e garrou a xingá eu mais a Maria Preta e disse que se o preço subir nós íamos acertar as contas no acampamento. (Cabral, Pedro Corrêa, 1993, Xambioá: Guerrilha do Araguaia)

Da mesma forma que nos exemplos anteriores, para a introdução da prótase (se o preço subir), o PV é mantido na Base (espaço que serve de âncora para a narrativa); em seguida, o narrador desloca o PV para o Espaço de Fala Passado (nós íamos acertar as contas no acampamento), conforme ilustra o Diagrama 5:

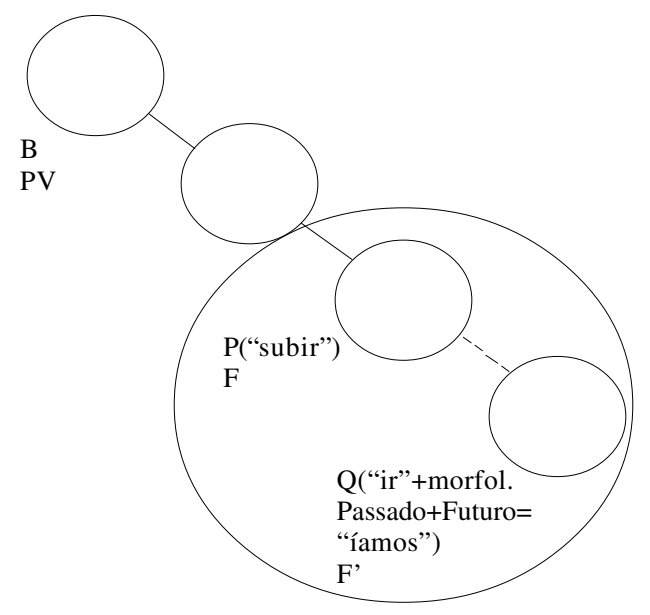

Diagrama 5 - Representação do exemplo 12 (...disse que se o preço subir nós íamos acertar as contas no acampamento)

No exemplo (12), o narrador compartilha com o falante reportado ("um deles") o ponto de vista a partir do qual se estabelece a hipótese de aumento do preço, mas o deslocamento do ponto de vista para o Espaço de Fala Passado (via Base) permite que o ato de fala reportado na apódose - uma ameaça - seja mantido no domínio discursivo do falante reportado (nós íamos acertar as contas no acampamento). 
É de se notar, ainda, que as diferentes possibilidades de alocação do ponto de vista na introdução de espaços condicionais podem permitir ocorrências de mesclagem entre discurso direto e indireto, em que o evento $P$ seja reportado indiretamente e o evento Q, diretamente. Vejamos o exemplo a seguir:

(13) O líder do PFL no Senado, Agripino Maia, disse que se o depoimento for retardado, "não tem alternativa senão a CPI do Silvinho". (www2.uol.com.br/oimparcial/090520061caderno.htm)

O uso de aspas no exemplo acima indica que a apódose foi introduzida diretamente do Espaço de Fala Passado; ao passo que a prótase havia sido acessada diretamente da Base. Nesse caso, não se verifica heterogeneidade de postura epistêmica no que se refere à estrutura temporal; como falante e falante reportado adotam postura epistêmica neutra, não há incompatibilidade entre tempos verbais. A heterogeneidade, nesse caso, refere-se aos participantes: ao ser introduzida a partir da Base, a prótase adota o PV do falante; por outro lado, ao tomar diretamente o Espaço de Fala como ponto de partida, a apódose adota o PV do falante reportado.

\section{Encaixe em espaços epistêmicos}

Tendo em vista que condicionais encaixadas em Espaço de Fala apresentam possibilidades variadas de alocação do ponto de vista, com consequientes reflexos na estrutura sintática dessas construções, a questão que se coloca em seguida é a do grau de generalidade do fenômeno. Pode-se concluir, com base no discurso reportado, que condicionais encaixadas em outros tipos de espaços apresentarão a mesma flexibilidade?

A resposta parece ser negativa. A análise dos dados demonstrou que a flexibilidade de ponto de vista não se verifica para as condicionais encaixadas em Espaços Epistêmicos, apesar de esses espaços serem introduzidos por verbos que atuam como construtores de espaços mentais (ex.: saber, pensar, achar).

Vejamos o que ocorre com os verbos "pensar" e "achar". Tais verbos sinalizam processos mentais referentes ao sujeito da conceptualização, mas não necessariamente ao falante. Por isso, uma sentença do tipo Dunga acha que jogos contra Peru e Uruguai serão difíceis destaca uma opinião sob o ponto de vista de Dunga (e não do redator). Isso porque, caso o redator compartilhasse do ponto 
de vista de Dunga, tenderia a dizer Dunga sabe que jogos contra Perue Uruguai serão difíceis. Analogamente, em uma sentença como Meu chefe pensa que estou trabalhando, trata-se também de uma opinião que se estabelece sob o ponto de vista do referido "chefe"; caso contrário, a versão mais apropriada da sentença seria Meu chefe sabe que estou trabalhando. ${ }^{9}$

Quando os verbos "achar" e "pensar" abrem espaços pretéritos, oPV deverá ser estabelecido nesses espaços, tendo em vista que a semântica desses verbos embute a idéia de que é o ponto de vista do conceptualizador (e não do falante/ redator) que está em destaque. É o que ilustram os exemplos a seguir, em que há encaixe de condicionais:

(14) Além disso, ele achou que se deixasse só crianças mutantes, a história poderia ficar infantilizada. Por isso, acrescentou esse poder ao meu personagem", ... (televisao.uol.com.br/ultnot/2007/05/09/ult4244u124.jhtm - 25k -)

(15) Ele pensou que se ele viesse para Seul ele poderia ganhar muito dinheiro. Porém, ao invés de ganhar dinheiro, ele somente ficou doente e sofreu muito ... (www.missaoboanoticia.com.br/htm/0804salvation.htm - 47k)

Os exemplos acima ilustram uma tendência categórica observada nos dados: ao se encaixarem em espaços epistêmicos de passado abertos pelos verbos "achar/pensar", as condicionais herdam necessariamente a estrutura de passado desses espaços. ${ }^{10}$

Com relação ao verbo "saber”, a situação é um pouco diferente. Quando digo que Maria sabe que a Terra é redonda, é porque compartilho, como falante, da crença de que $A$ Terra é redonda. Em outras palavras, a semântica do verbo "saber" exige que falante e sujeito da conceptualização compartilhem o mesmo ponto de vista na Base.

Nos casos de uso do verbo "saber" no passado, entretanto, abrem-se duas possibilidades. Tanto é possível manter o PV na Base ("Maria soube que a Terra é redonda"), quantoé possível que o PV se desloque para o espaço passado ("Maria soube que a Terra era redonda"). A opção de deslocar o PV para o espaço passado parece estar ligada ao fato de que a informação compartilhada na Base (" $a$ Terra é redonda") pode ser transferida "por default" para os espaços subordinados. Sendo assim, o deslocamento do PV não entra em choque com as exigências semânticas do verbo (a informação compartilhada na Base licencia o uso do verbo 
"saber", mas a possibilidade de transferência da informação para espaços encaixados permite a transferência posterior do PV).

Construções condicionais podem ter, portanto, dupla possibilidade de encaixe em espaços abertos por "saber". Se o PV está na Base, verificam-se exemplos do tipo abaixo:

(16) Soube que se o Coríntians perder na Justiça do Trabalho, vai recorrer à FIFA, para ficar com os direitos federativos de Max . ... (www.radioglobonatal.com.br/blog/marcos/2007/05/16/novela_max_ pode_ser_bem_mais_longa )

Por outro lado, se a condicional se refere a eventos passados, $\mathrm{o} P \mathrm{~V}$ poderá deslocar-se para o espaço passado:

(17) Do site da RFM fui para o site da Cow Parade, li tudo o que tinha a ler, guardei os guias para ler, etc...até que soube que se fossemos escolhidos tinhamos que ir para Lisboa pintar. (:/_espiritonorte.blogspot.com/2006/ 04/como-tudo-comeou_25.html - 23k )

Em resumo, podemos concluir que há um continuum de flexibilização do ponto de vista em condicionais encaixadas, de modo que os verbos "achar/ pensar" determinam que o ponto de vista se estabeleça obrigatoriamente no espaço epistêmico; o verbo "saber" admite uma escolha para o estabelecimento do ponto de vista (na Base ou no Espaço Epistêmico), mas uma vez que a escolha tenha sido feita não poderá haver deslocamento; os verbos de fala ("dizer", "falar", "comentar", etc) não só admitem que se opte pela alocação do ponto de vista na Base ou no Espaço de Fala, mas também não exigem que a escolha seja definitiva (o PV pode se manter na Base para a introdução da prótase e ser deslocado da Base para o Espaço de Fala para a construção da apódose).

\section{Conclusão}

O presente trabalho enfocou construções condicionais encaixadas, com o objetivo de rediscutir a noção de uniformidade de postura epistêmica, tradicionalmente aceita na literatura referente a condicionais. Com base em exemplos atestados, a análise demonstrou que se observam casos de uniformidade e nãouniformidade de postura epistêmica, que não podem ser explicados em função 
de restrições sintáticas inerentes às construções condicionais, mas resultam de fatores semânticos e discursivo-pragmáticos definidos com base nas ferramentas teóricas oferecidas pela teoria dos espaços mentais.

Inicialmente, demonstrou-se que há três relações possíveis entre ponto de vista e postura epistêmica para o encaixamento de condicionais em Espaços de Fala, a saber: a. uniformidade de postura epistêmica com ponto de vista na Base; $b$. uniformidade de postura epistêmica com ponto de vista deslocado para o Espaço de Fala (via Base); c. heterogeneidade de postura epistêmica com ponto de vista inicialmente alocado na Base, e posteriormente, alocado no Espaço de Fala (via Base).

O trabalho argumentou, ainda, que o encaixe de condicionais em Espaços de Fala decorre de características semânticas dos verbos dicendi associadas a estratégias específicas de alocação de ponto de vista. Isso explica por que verbos epistêmicos, cuja semântica já prevê informações mais rígidas sobre ponto de vista, não autorizam estratégias tão flexíveis de encaixe de condicionais quanto os verbos dicendi.

Vale destacar, ainda, que na medida em que se verifica que os fatores que determinam a estrutura sintática das condicionais encaixadas são de natureza cognitivo-discursiva, e que o mesmo ambiente sintático (tradicionalmente, orações completivas) pode exigir diferentes combinações modo-temporais, o trabalho constitui uma evidência importante para o hipótese de que construções gramaticais resultam de uma estreita correlação entre sintaxe e semântica/pragmática.

\section{Notas}

${ }^{1}$ Segundo a autora, a noção de "suficiente" é estabelecida levando-se em conta o mundo real, não possuindo o sentido lógico de (necessário e) suficiente. Embora muitas vezes as condicionais sugiram uma leitura do tipo "se e somente se", Comrie (1986) argumenta que essa leitura não é parte da semântica da conjunção se, mas resulta de uma implicatura conversacional.

${ }^{2}$ Fillmore não associou inicialmente a noção de postura epistêmica às condicionais de conteúdo, já que não havia ainda uma classificação das condicionais nos moldes que seriam propostos em seguida por Sweetser (1990). Entretanto, como seus exemplos envolvem o que Sweetser tratou como condicionais de conteúdo, pode-se considerar que o fenômeno da coerência de postura epistêmica foi inicialmente postulado para as condicionais de conteúdo. Tendo em vista que estudos posteriores demonstraram que as restrições temporais nas condicionais de conteúdo são mais rígidas do que nas 
epistêmicas e pragmáticas (DANCYGIER, 1998; DANCYGIER; SWEETSER, 2005), a discussão que proponho neste artigo visa a demonstrar que, mesmo nas condicionais de conteúdo, a coerência de postura epistêmica não é categórica.

${ }^{3}$ Há também a possibilidade de que o falante conceba o mundo representado na prótase como sendo compatível com o mundo real. Nesse caso, entretanto, utilizaria uma construção temporal (Quando o Fluminense ganhar a Copa do Brasil, seus torcedores comemorarão).

${ }^{4}$ Se o PV fosse deslocado para o Espaço de Fala Passado (via Base), a codificação verbal teria que ser "queimaria".

${ }^{5}$ As construções temporais exibem postura real ou assumida, em que o falante associa-se mentalmente ao mundo descrito na prótase (ex.: Quando eu terminar o trabalho, farei compras).

${ }^{6}$ A escolha do presente do indicativo também é possível (Se chover, eles cancelam o jogo). Nesse caso, o que ocorre é o que Dancygier (2003) denominou temporal backshifting (recuo temporal); trata-se de um uso do tempo presente com valor cronológico de futuro. Sendo assim, mantém-se a coerência de postura epistêmica, já que ambos os tempos verbais apontam para eventos presentes ou futuros, a partir de uma postura epistêmica neutra.

${ }^{7}$ Se a referência temporal do evento "viajar às duas" é passado em relação ao Espaço Base e futuro em relação ao Espaço de Fala, o ponto de vista terá necessariamente que ser alocado no Espaço de Fala (Ela disse que Ana viajaria às duas). Mas, se o evento for futuro em relação ao Espaço Base e ao Espaço de Fala, verifica-se dupla possibilidade de alocação do ponto de vista : no Espaço Base (Ela disse que Ana viajará às duas) ou no Espaço de Fala (Ela disse que Ana viajaria às duas). Nesse caso, a escolha do falante parece ser influenciada por fatores pragmáticos, que mereceriam um estudo à parte.

${ }^{8}$ Como demonstram Dancygier e Sweetser (2005), é possível usar a morfologia de passado com camadas "duplas" para indicar tempo passado e postura epistêmica distanciada. Entretanto, uma outra camada de morfologia temporal não costuma ser herdada de um Espaço de Fala Passado, se a postura epistêmica distanciada já estiver marcada na condicional. Os exemplos a seguir ilustram esse fenômeno:

(1) Se João jogasse na loteria, ficaria rico.

Em (1), há uma camada única de morfologia de passado, que marca postura epistêmica contrafactual (e não tempo passado, já que o falante pode estar se referindo ao momento presente ou ao futuro). Se, entretanto, encaixarmos a condicional em um Espaço de Fala Passado, a estrutura temporal se manterá inalterada: 
(2) Maria disse que, se João jogasse na loteria, ficaria rico.

No exemplo a seguir, a dupla camada de morfologia indica tempo passado e postura epistêmica contrafactual:

(3) Se João tivesse jogado na loteria, teria ficado rico.

Entretanto, ao encaixarmos a condicional em um Espaço de Fala Passado, a estrutura temporal também se mantém inalterada:

(4) Maria disse que, se João tivesse jogado na loteria, teria ficado rico.

O que se verifica, nesses casos, é que não há marcação morfológica extra para sinalizar o ponto de vista do Espaço de Fala Passado em condicionais que já utilizam morfologia de passado. A regra geral é, portanto, a seguinte: se a condicional já usa morfologia de passado para marcar postura epistêmica contrafactual, uma segunda camada de morfologia não é herdada de um Espaço de Fala Passado mais alto. Da mesma forma, quando a condicional já marca originalmente postura epistêmica contrafactual e tempo passado, não é possível adicionar uma terceira camada de morfologia de passado para encaixá-la em um Espaço de Fala.

${ }^{9}$ Vale notar que, embora os verbos "achar" e "pensar" exijam que o ponto de vista se estabeleça no espaço epistêmico, há uma sutil diferença semântica entre ambos no português brasileiro. No caso de "achar", o falante mantém postura epistêmica neutra com relação à proposição encaixada (ex... "achar que X" admite uma leitura em que X está na Base e no espaço de crença (Maria acha que as frutas estão maduras e de fato, estão), mas também uma leitura em que o sujeito se equivoca em sua avaliação (Maria acha que as frutas estão maduras - mas ainda não estão) ; já no caso de "pensar", a inferência convencionalizada é de que a proposição X não se sustenta na Base (ex.: "pensar que X" implica necessariamente que o sujeito está equivocado - Maria pensa que as frutas estão maduras - mas, na verdade, não estão).

${ }^{10}$ Deve-se excluir apenas os casos em que o verbo "achar" é usado como dicendi. Nesse caso, o PV pode ser manter na Base porque se trata de discurso reportado e não de processo epistêmico. 


\section{Referências Bibliográficas}

CHOMSKY, N. Language and Mind. New York: Harcourt Brace Jovanovich, 1968.

CHOMSKY, N. Rules and Representations. Behavioral and Brain Sciences 3, p.1-61, 1980.

COMRIE, B. A typology of conditionals. In: TRAUGOTT, E. et al (Ed.). On conditionals. Cambridge: Cambridge University Press, 1986.

CUTRER, M. Time and Tense in Narratives and everyday language. Ph.D. Dissertation. University of California, San Diego, 1994.

DANCYGIER, B. Conditionals and Prediction. Cambridge: Cambridge University Press, 1998.

DANCYGIER, B. Classifying Conditionals: Form and Function. English Language and Linguistics 7(2), p. 309-23, 2003.

DANCYGIER, B.; SWEETSER, E. Conditionals, Distancing, and Alternative Spaces. In: GOLDBERG, A. (Ed.). Conceptual Structure, Discourse and Language. Stanford, California: CSLI Publications, 1996. p. 83-98.

DANCYGIER, B.; SWEETSER, E. Mental Spaces in Grammar. Conditional Constructions. Cambridge: Cambridge University Press, 2005.

DINSMORE, J. Partitioned Representations. Dordrecht: Kluwer, 1991.

FAUCONNIER, G. Mental Spaces. Cambridge: Cambridge University Press, 1985[1994].

FAUCONNIER, G. Analogical Counterfactuals. In: DANCYGIER, B.; SWEETSER, E. (Ed.). Spaces, Worlds and Grammar. Chicago: Chicago University Press, 1996. p. 57-90.

FAUCONNIER, G. Mappings in Thought and Language. Cambridge: Cambridge University Press, 1997.

FAUCONNIER, G.; SWEETSER, E. (Ed.). Spaces, Worlds and Grammar. Chicago: Chicago University Press, 1996.

FAUCONNIER, G.; TURNER, M. The Way We Think. Conceptual Blending and the Mind's Hidden Complexities. New York: Basic Books, 2002.

FILLMORE, C. Frame Semantics. In: Linguistic Society of Korea (Ed.). Linguistics in the Morning Calm. Seoul: Hanshin, 1982.

FILLMORE, C. Epistemic Stance and Grammatical Form in English Conditional Sentences. Papers from the Twenty-sixth Regional Meeting of the Chicago Linguistic Society, p.137-162, 1990. 
FILLMORE, C.; KAY, P.; O'CONNOR, C. Regularity and Idiomaticity in Grammatical Constructions: the Case of Let Alone. Language 64, p.501-538,1988.

GOLDBERG, A. Constructions: A Construction Grammar Approach to Argument Structure. Chicago: University of Chicago Press, 1995.

GOLDBERG, A. Constructions at Work. Oxford: Oxford University Press, 2006.

LAKOFF, G. Women, Fire and Dangerous Things. Chicago: University of Chicago Press, 1987.

LANGACKER, R.Foundations of Cognitive Grammar V. I: Theoretical Prerequisites Standford CA: Stanford University Press, 1987.

LANGACKER, R. Foundations of Cognitive Grammar. V. II Theoretical Prerequisites. Standford CA: Stanford University Press, 1991.

SWEETSER, E. From Etymology to Pragmatics. Cambridge: Cambridge University Press, 1990.

TOMASELLO, M. Constructing a Language; A Usage Based Theory of Language Acquisition. Cambridge: Harvard University Press, 2005. 